\title{
Editorial: The legacy of early radiolarian taxonomists
}

Modern applied scientific studies using groups of organisms are built on a still incomplete framework of taxonomic research extending back to the foundations of modern biology in the early nineteenth century. The strengths and weaknesses of a group's taxonomy often reflect the legacy of influential individual taxonomists, and understanding this illuminates how history still affects current research. Radiolarians are single-celled marine plankton whose shells, when formed out of opaline silica (i.e. group Polycystinea) are common also as fossils in marine sediments and older rocks. They are used today mostly for applied research on geological age dating or past climate change. The four papers in this thematic set represent a first attempt to explore this legacy for radiolarians, and grew out of a symposium on early radiolarian taxonomy held during the 12th International Radiolarian Congress (2009, Nanjing). Radiolarian taxonomic research first developed in Europe and the papers here discuss facets of this early work. It should, however, not be forgotten that modern research also builds on a legacy of taxonomic studies in other countries, particularly America, Russia and Japan.

The individual papers take very different approaches to studying this early taxonomic legacy. The first paper by Lazarus (2014) makes use of newly available compilations of radiolarian species names to give a statistical summary of radiolarian taxonomists, and how taxonomic research developed over time. Radiolarian studies clearly developed in two rather discontinuous phases in the late nineteenth and late twentieth centuries. Nineteenth-century German taxonomists are the main focus of this paper, and the summaries of several workers' activities make clear how very different their approaches were to this subject. The earliest worker, C. G. Ehrenberg, studied virtually all types of micro-organisms, and described thousands of new species (including hundreds of radiolarians), but relatively few higher taxa within radiolaria. Many of Ehrenberg's species are still in use, and recent re-examination of his collections will most likely increase this percentage in the future. Haeckel, by contrast, published not only thousands of new radiolarian species names but established an elaborate higher-level taxonomic framework for the group. Lazarus argues, however, that the higher-level framework was created more from Haeckel's interest in evolutionary theory than from objective observations, and led to not only a great deal of artificial duplication of species and other lower-level taxa, but that it also established an unfortunate style of artificial higher-level taxonomy that many later workers followed. Only a few percent of Haeckel's vast legacy of species names are still in use today. This paper also points out the lasting negative effect caused by the loss of many of these early workers' collections during World War II: without type materials and often inadequate descriptions, many species names were left in a nomenclatural limbo that impeded the development of a practical taxonomy for modern research needs.

The two papers of Dolven et al. (2014) and Bjørklund et al. (2014) give a biogeographical summary, and examine the specific taxonomy of individual Scandinavian workers (Jørgensen and Cleve, respectively). In each case they provide a detailed review of these workers' species concepts. Although Jørgensen and Cleve together published only c. 50 new species names for radiolarians, many of these are still in use and, because - unlike those of many early German workers - their original materials are still preserved in museums, the taxonomic legacy is secured here by re-documentation via new photographs and, importantly, by designation of proper type specimens. Neither of these workers, interestingly, was primarily a radiolarian specialist: Jørgensen devoted most of his career to botany, and Cleve was a prominent chemist (who in the course of his career discovered two of the elements).

Lastly, Cortese (2014) provides an overview of early Italian radiolarian studies, including brief biographies of several workers, such as Pantanelli, who was an important early researcher of Mesozoic radiolarians and their application to dating geological formations. He also summarizes the cross-linkages between early German workers, such as Haeckel, Italian workers, and the development of the Zoological Station in Naples by one of Haeckel's students, A. Dohrn. This example reminds us of the importance of institutions and infrastructure to the growth of science, and the role that individuals play in their development. The main focus of Cortese's paper is, however, on an aspect of taxonomic history rarely documented: 'might-have-beens', e.g. workers who showed great promise, but for whatever reason did not make a major impact on taxonomic knowledge. Specifically, he reviews the work of a little-known student of radiolarians, P. Enriques, who had in his thirties begun a major taxonomic revision of the group, with the goal of providing a by then much-needed (as the paper by Lazarus points out) biological foundation for higher-level radiolarian taxonomy. Tragically, Enriques died in a car accident a few years later, and this potentially seminal monograph was never published, although the manuscript is still stored at the Naples Zoological Station. Taxonomic science is as much a product of the chance events of individual history, as are the organisms it studies.

\section{ACKNOWLEDGEMENTS}

I am grateful to F. John Gregory and Sarah Gibbs for their editorial and production work respectively in support of this set of thematic papers.

\section{REFERENCES}

Bjørklund, K.R., Itaki, T. \& Dolven, J.K. 2014. Per Theodor Cleve: a short résumé and his radiolarian results from the Swedish Expedition to Spitsbergen in 1898. Journal of Micropalaeontology, 33, 59-93.

Cortese, G. 2014. Radiolarian researchers based in Italy during the late nineteenth and early twentieth centuries. Journal of Micropalaeontology, 33, 95-103.

Dolven, J.K., Bjørklund, K.R. \& Itaki, T. 2014. Jørgensen's polycystine radiolarian slide collection and new species. Journal of Micropalaeontology, 33, 21-58.

Lazarus, D. 2014. The legacy of early radiolarian taxonomists, with a focus on the species published by early German workers. Journal of Micropalaeontology, 33, 3-19.

DAVID LAZARUS

Museum für Naturkunde, Invalidenstrasse 43, D-10115 Berlin, Germany (e-mail: david.lazarus@mfn-berlin.de) 
